\title{
INFLUENCE OF THE CONSTRUCTIVE AND Operational Features ON THE CENTRIFUgeS
}

\author{
BOIANGIU, M. \& BOIANGIU, A.
}

Abstract: In this paper is proposed a field of advanced fundamental research: the study of vibrations of industrial centrifuges considering the constructive and functional factors. It will be established special study model for centrifuges, as discrete system with two degrees of freedom. It will be studied the influence of the constructive and working specific features of these machines (shaft position, centrifugal basket position, bearings putting, unbalancing). It must be taken into account the influence of the gyroscopic moment. The paper proposes new approaches in the subject field and also develops existing theories and methods.

Key words: centrifuge, vibrations, natural frequencies, operational features.
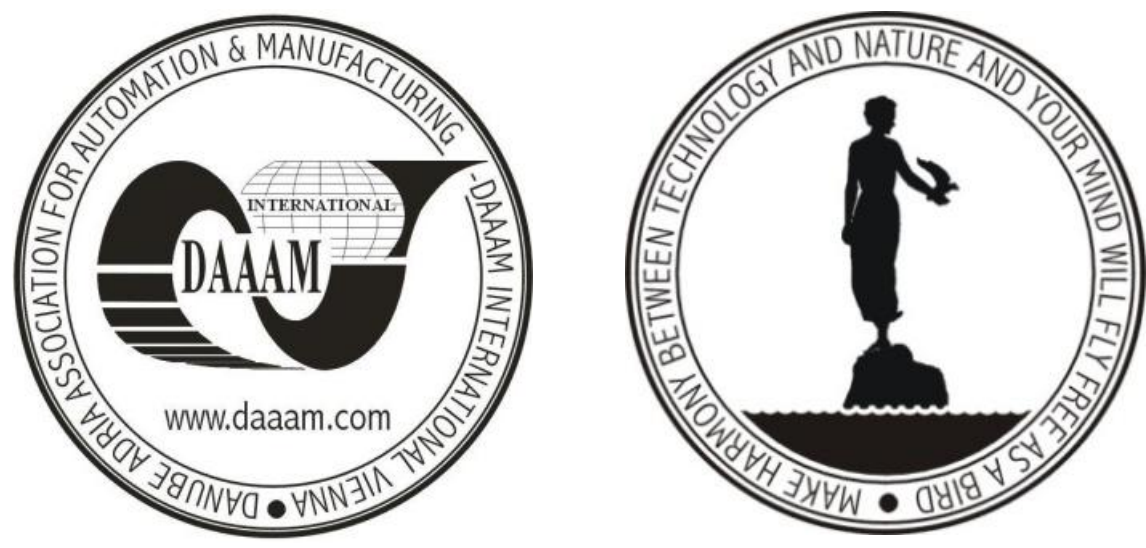

Authors' data: Univ.Assoc. Prof. Dipl.-Eng. Dr.techn. Boiangiu, M[ihail]*; Dipl.Eng. Prof. Boiangiu, A[dina]**, *"Politechnica" University of Bucharest, Department of Mechanics, Splaiul Independentei, no.313, 060042, Bucharest, Romania, **Technical College "Edmond Nicolau", Bucharest, mboiangiu@gmail.com, adboiangiu@gmail.com

This Publication has to be referred as: Boiangiu, M[ihail] \& Boiangiu, A[dina] (2010). Influence of the Constructive and Operational Features of the Centrifuges, Chapter 40 in DAAAM International Scientific Book 2010, pp. 445-462, B. Katalinic (Ed.), Published by DAAAM International, ISBN 978-3-901509-74-2, ISSN 17269687, Vienna, Austria

DOI: $10.2507 /$ daaam.scibook.2010.40 
Boiangiu, M. \& Boiangiu, A.: Influence of the Constructive and Operational Featu...

\section{Introduction}

Centrifugal action is a mechanical process, which allows the acceleration separation of the components of heterogeneous systems. The machine that realizes this process is named centrifuge. Theoretical, these are composed by a shaft that has mounted a centrifugal basket (figure 1). The shaft that is quiet in bearing can be horizontal positioned (figure 1.a, c) or upright (figure 1.b). Centrifugal basket can be assembled between the bearings (figure 1.c), or in cantilever (figure 1.a).

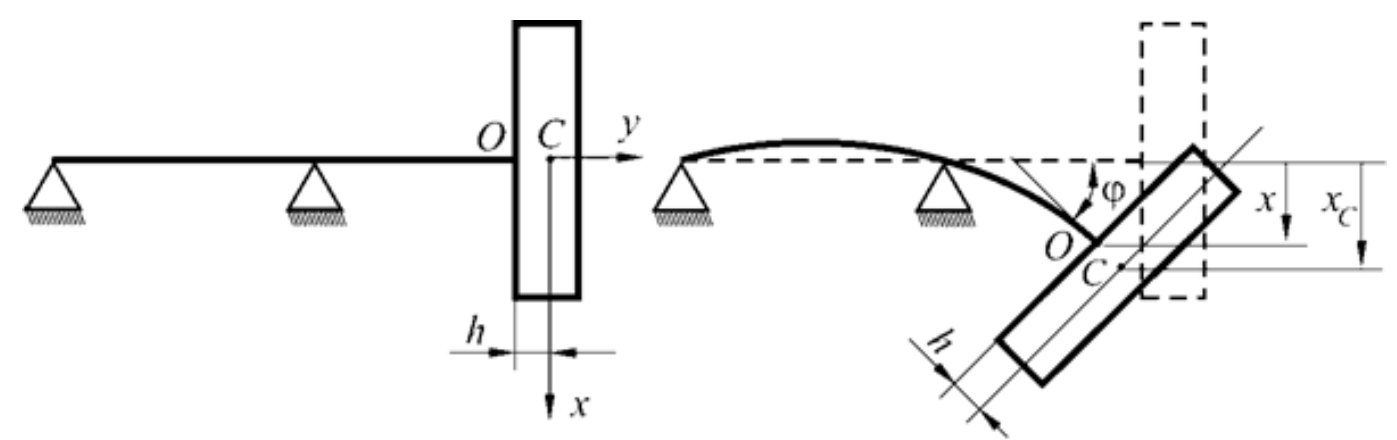

a)
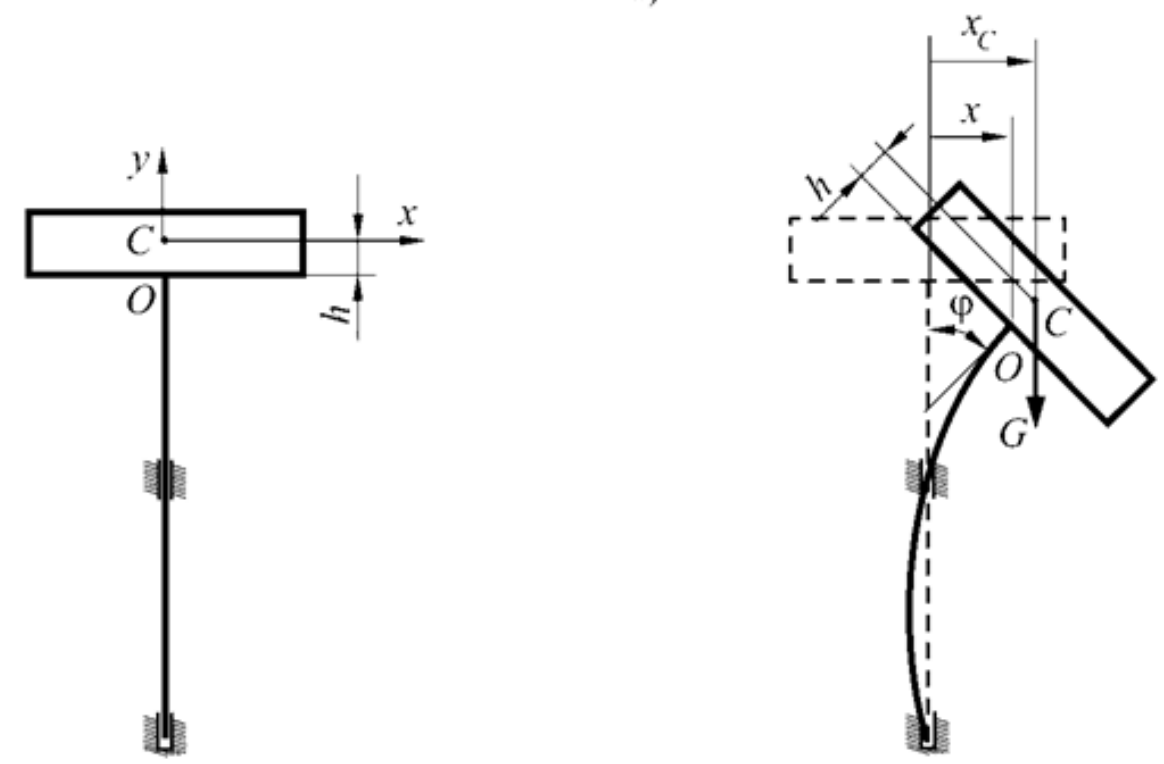

b)
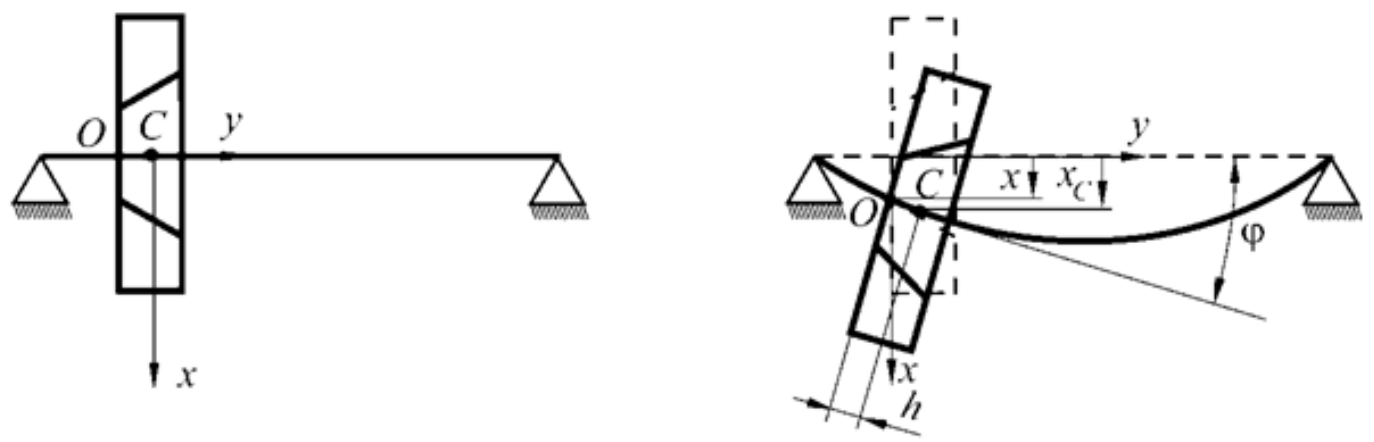

c)

Fig. 1. Types of centrifuges

There are books that include chapters with the approximate and construction of 
centrifuge (Jinescu, 1988). Anyway the reserved chapter of the dynamic behaviour of these machines is small, and the problem is treatise through very simplify methods. In some books there is not approach about centrifuge vibration (Sutherland \& Records, 2001). In the field of activities are only few paper works, or this aim is not about the dynamics centrifuge machine. Some paper works treat the approximate and construction of the subassembly (Iatan et al., 1990), and other refers to the separation process of blending stock (Haeberle et al., 2005; Stiborsky\&Anlauf, 2003).

Centrifuges are revolution machines with unbalancing from the construction and working. The centrifugal basket cannot be perfect equilibrium executed (from the technological reasons). If, after the centrifugal basket is mounted on shaft, the system shaft - centrifugal basket can be balancing (static and dynamic), in the movement of the centrifuge the materials who move apart from the heterogeneous blending don't fall out very uniform on the surface of the centrifugal basket, and the centrifuge is unbalancing. Because of these in action absolutely come on induced vibrations.

The hereby document deals with the calculation of the critical angular speed (the critical speed) of the shaft. By knowing these critical speed, it will be avoided the operation of the centrifuge at these speed or around this kind of speed.

Figure 1 presents the view of the vertical/horizontal centrifuge with the basket in the console/between the bearings. " $G$ " represents the weight of the basket, together with the operating material (fluid).

As regards the study of the bending vibrations, the centrifuges may be adapted in two ways:

as a discrete system, with a finite number of degrees of freedom, which is composed of a flexible shaft of negligible weight, placed on two supports, and of a basket fixed on the shaft (between the supports or in the console);

- as a flexible shaft, considered a continuous medium (having an infinite number of degrees of freedom) placed on two supports and a basket fixed on the shaft (between the supports or in the console).

The hereby documentation uses the model with two degrees of freedom. This kind of model, although it represents a simplified kind of centrifuge, offers the possibility of a good quality and quick study of the dynamic behaviour of the centrifuge.

When the shaft is in horizontal position, with the basket fixed on the shaft, between the supports or in the console (figure 1.a, c), the weight of the basket shall not be taken into consideration. The weight force of the basket and, possibly, the moment of the gravitational force trigger a static deformation of the shaft. The subsequent oscillatory movement is overlapping with this static deformation.

As opposed to the horizontal centrifuge, when studying the bending vibrations of a vertical centrifuge, one should consider the weight of the basket (plus the operating material) (figure 2.c). The weight force of the basket realizes mechanical work and contributes to the oscillatory movement. This paper studies the extent in which the weight force influences the values of the natural frequencies. The weight force of the basket is reduced in its fixing point on the shaft, $O$, at a force $G=m g$ and a moment $M_{G}=m g \cdot h \sin \varphi$ (figure 2.c). Because the angle $\varphi$ takes low values, 
the approximation $\sin \varphi \approx \varphi$ can be done. Thus, the elements of reducing of the weight forces in the fixing point of the basket on the shaft are (figure 2.d):

$$
\tau_{O}^{G}\left\{\begin{array}{l}
G=m g \\
M_{G}=m g h \varphi
\end{array}\right.
$$

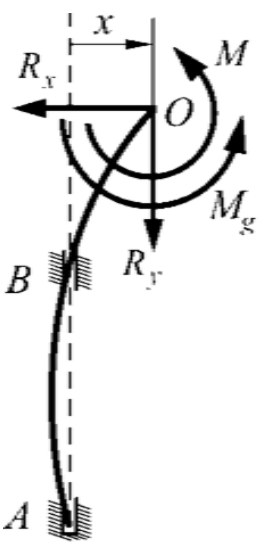

a)

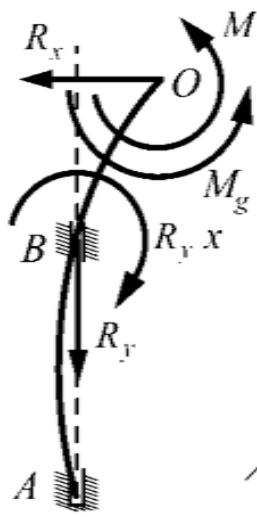

b)

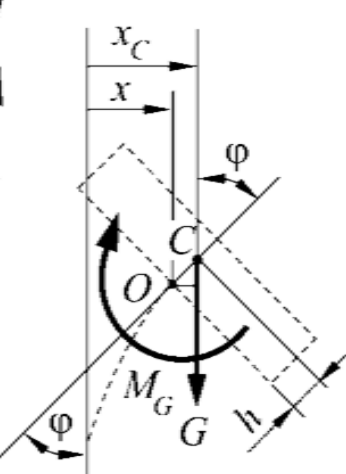

c)

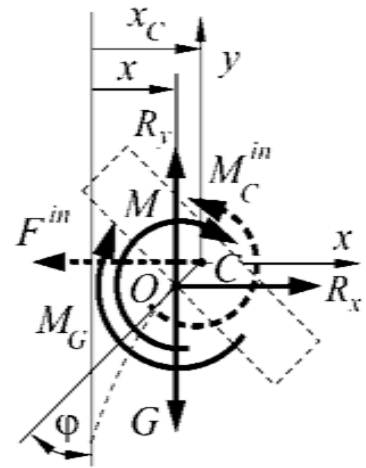

d)

Fig. 2. Vertical centrifuge. Considering of the weight force. Calculus of reactions in the fixing point of the basket on the shaft. Action of the gyroscopic moment

Because there is an interest in the determination of the critical speeds, only the free undamped vibrations are studied. If the critical speeds cannot be avoided and the centrifuge is operating at almost critical speeds, the amplitudes of the bending vibrations can be reduced by installing a damper or a vibration dynamic absorber. The possibility to control the bending vibrations via these methods shall make the topic of a separate work.

The disturbing force may appear as a result of the fact that the weight centre of the basket is not on the rotation axis. This phenomenon can appear also during operation, because of the uneven material deposits on the basket or because of the damages during operation.

By choosing the system of axes presented at figure 3, with the $O y$ axis along the shaft, so in perpendicular position on the basket, the bending vibrations shall be studied in the $x O y$ plane.

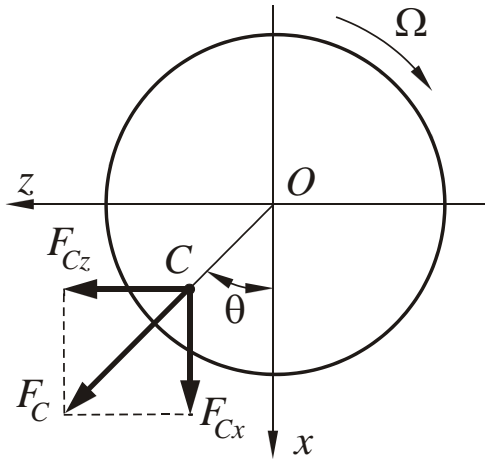

a)

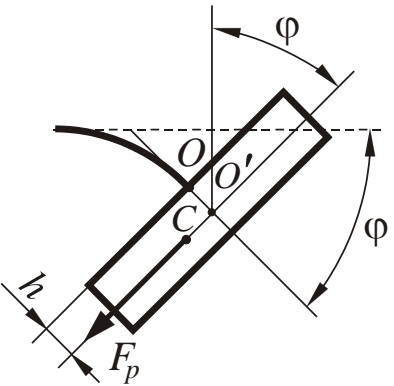

b)

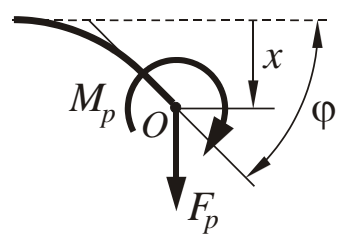

c)

Fig. 3. The disturbing force and its reduction in the fixing point of the basket 
Consequently, the elements of reduction of the system of disturbing forces in the $O$ point are (figure 3.c):

$$
\tau_{O}^{p}\left\{\begin{array}{c}
F_{p}=m e \Omega^{2} \cos \Omega t \\
M_{p}=m e h \Omega^{2} \cos \Omega t
\end{array}\right.
$$

where: $m$ is the mass of the basket; $\Omega$ - the angular speed of the shaft-basket system; $e$ - the eccentricity $(O C=e)$.

A factor that influences the values of the natural angular frequencies is the gyroscopic moment. When the basket is not fixed in the middle of the distance between the bearings or it is in the console, the gyroscopic phenomenon will appear. The gyroscopic moment (figure 4) modifies the bending deformation.

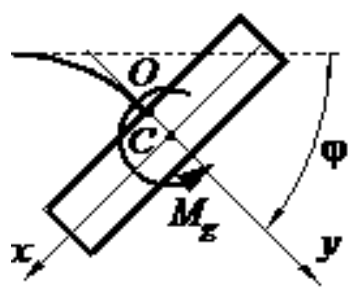

a)

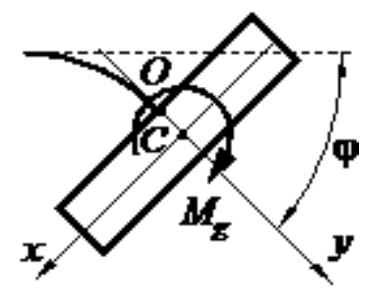

b)

Fig. 4. The influence of the gyroscopic moment on a shaft with the basket in theconsole, in the case of the forward (a) or backward (b) precession

If the bending plane (the plane where the basket supports bends via vibrations) and the shaft are rotating in the same direction with the same angular speed $\omega=\Omega$, the movement is forward synchronous rotation. The module of the gyroscopic moment is $M_{g}=\left(J_{y}-J_{z}\right) \Omega^{2} \varphi$, where: $J_{x}=J_{z}$ and $J_{y}$ represent the mass moments of inertia with respect to the $O x, O z$ axes and respectively $O y ; \omega$ - the angular speed of the bending plane (the plane where the basket supports bends via vibrations); $\varphi$ - the inclination of the shaft in the centre of mass section of the basket.If the bending plane and the shaft are rotating in the opposite ways, but with the same angular speed $\omega=\Omega$, the movement is backward synchronous rotation. The module of the gyroscopic moment is $M_{g}=\left(J_{y}+J_{z}\right) \Omega^{2} \varphi$.

Regarding the position of the centre of mass with respect the fixing point of the basket on the shaft three situations are in the case of the console centrifugal basket and also if the centrifugal basket is assembled between the bearings: the fixing point of the basket $(O)$ stands between the centre of mass $(\mathrm{C})$ and the bearing (figure 5.a); the centre of mass coincides with the fixing point of the basket (figure 5.b); the centre of mass is between the fixing point of the basket and the bearing (figure 5.c). When the centrifugal basket is assembled between the bearings other two cases exist: the fixing point of the basket is situated at the middle of the shaft but it doesn't coincide with the centre of mass of the basket (figure 5.d); the fixing point of the basket is situated at the middle of the shaft and it coincides with the centre of mass of the basket (figure 5.e). 

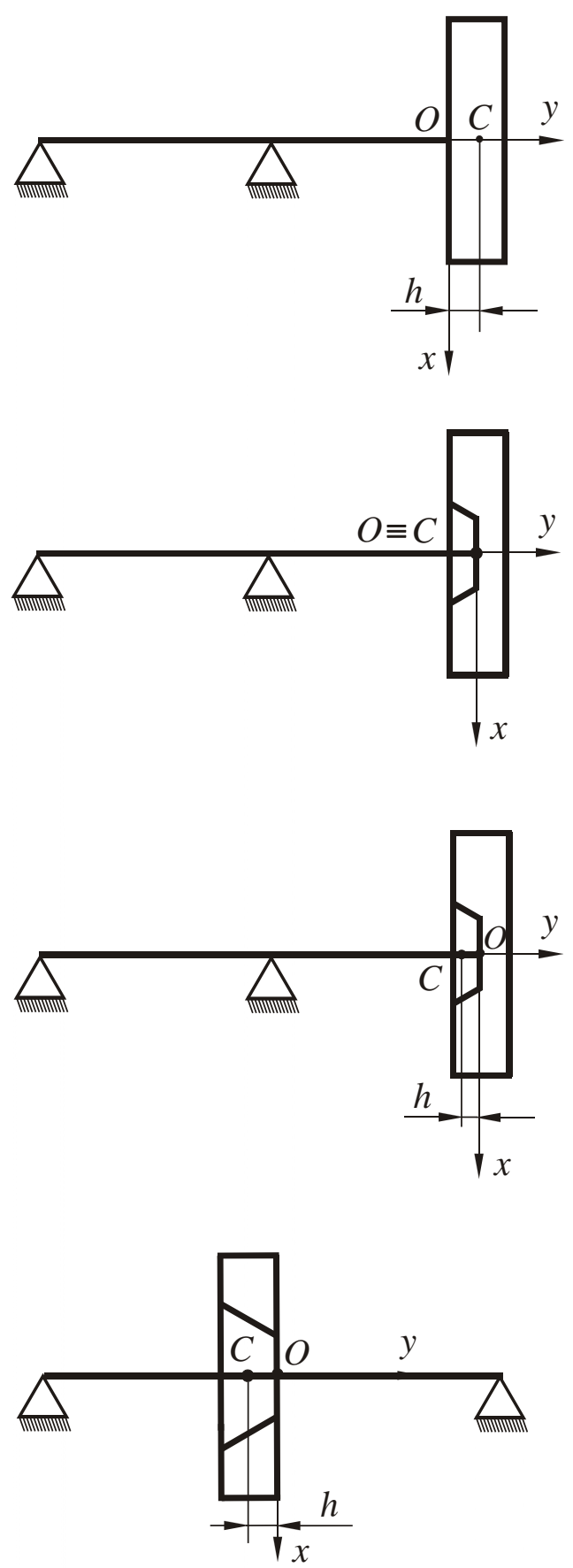

d)

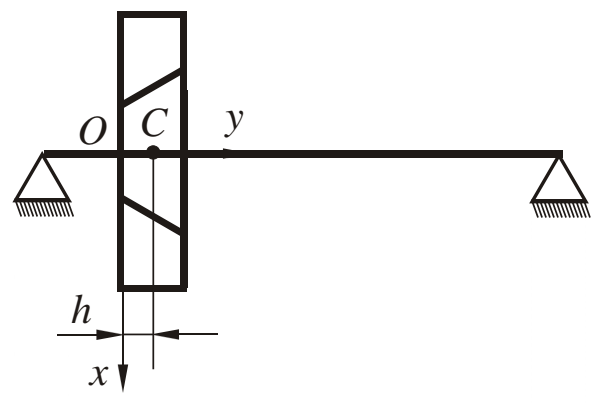

a)

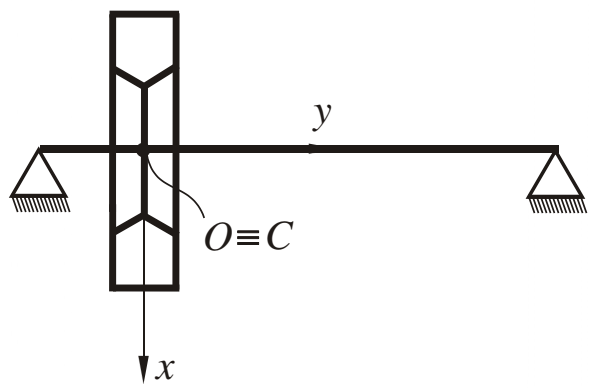

b)

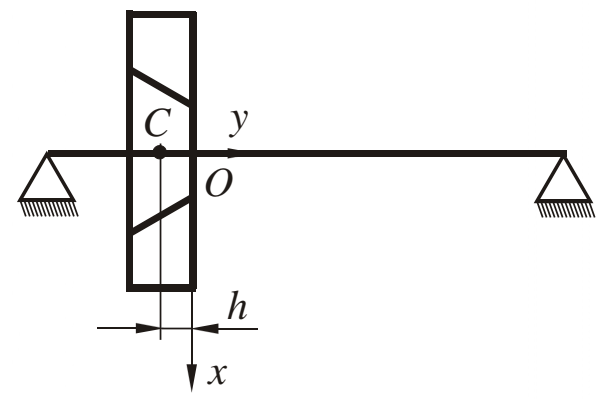

c)

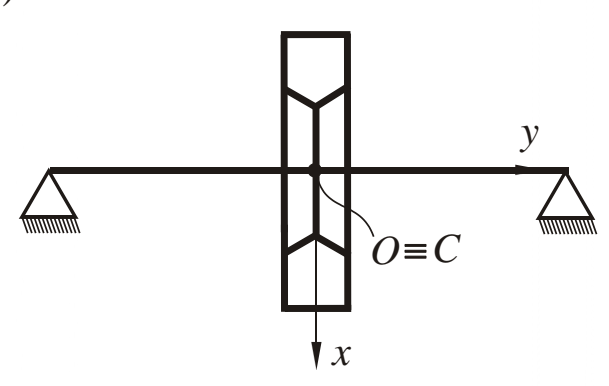

e)

Fig. 5. Position of the fixing point of the basket on the shaft with respect the centre of mass of the basket and the bearings

For demonstration and calculus, it is considered a horizontal centrifuge with the basket in console.

\section{Horizontal centrifuge with the basket in console}

\subsection{The fixing point of the basket is between the centre of mass and the bearing}

The model used for the study is the one with two degrees of freedom. The basket is embedded in the shaft. The basket is considered to have a motion parallel to a fixed 
plane. The two parameters are the following: $x_{C}$ - the vertical displacement of the centre of mass of the basket; $\varphi$ - the rotation around the $O z$ axis of the median plane of the basket.

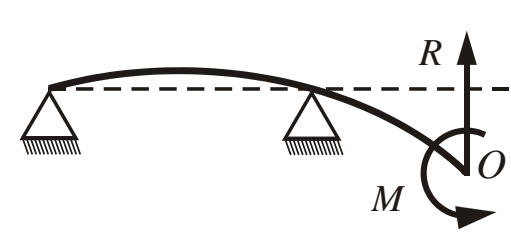

a)

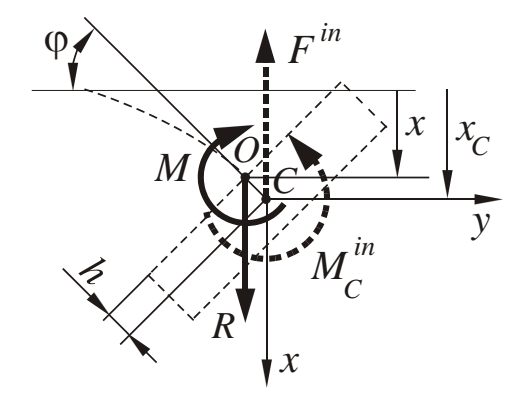

b)

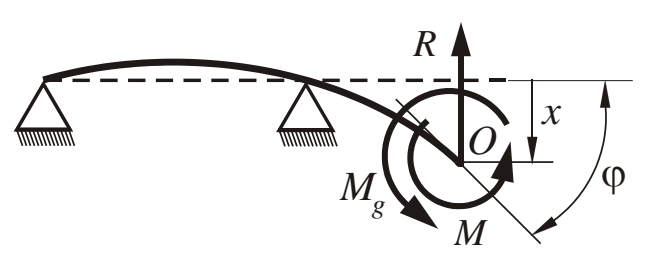

c)

Fig. 6. Calculus of reactions in the fixing point of the basket on the shaft. Theaction of the gyroscopic moment

In order to write the differential equations of the movement, it is used the method of the coefficients of influence. For the calculation of the $\mathrm{R}$ and $\mathrm{M}$ reactions in $O$ (figure 6.a), the basket shall be isolated and it shall be applied the d'Alembert's principle (figure 6.b). The following will be obtained:

$$
\left\{\begin{array}{l}
R=m \ddot{x}_{C} \\
M=m \ddot{x}_{C} h \cos \varphi+J_{C z} \ddot{\varphi}
\end{array}\right.
$$

Finally, it is obtained:

a) The case of the forward precession (figure 5)

$$
\left\{\begin{array}{c}
x=-\left(\delta_{F}+\delta_{M} h\right) m \ddot{x}-\left[\delta_{F} m h+\delta_{M}\left(m h^{2}+J_{C Z}\right)\right] \ddot{\varphi}-\delta_{M}\left(J_{C y}-J_{C Z}\right) \Omega^{2} \varphi \\
\varphi=-\left(\alpha_{F}+\alpha_{M} h\right) m \ddot{x}-\left[\alpha_{F} m h+\alpha_{M}\left(m h^{2}+J_{C Z}\right)\right] \ddot{\varphi}-\alpha_{M}\left(J_{C y}-J_{C Z}\right) \Omega^{2} \varphi
\end{array}\right.
$$

where:

$\delta_{F}$ and $\delta_{M}$ are the coefficients of influence that represent the displacements in the $O$ point, generated by a force, and, respectively, by a moment equal with the unity; $\alpha_{F}, \alpha_{M}$ - the coefficients of influence that represent the rotations in the $O$ point, these rotations being generated by a force, and, respectively, by a moment equal with the unity; $\Omega$ represents the angular speed of the shaft; $J_{C Z}$ - the mechanic moment of inertia of the basket with respect to the $C z$ axis that passes through the centre of mass and that is perpendicular on the surface of the drawing; $J_{C y}$ - the mechanical moment of inertia of the basket with respect to the $C y$ axis that passes through the centre of mass and that is the rotation theoretical axis.

There are demanded synchronous (the same angular frequency $\omega$ ) and in phase solutions like the following:

$$
\left\{\begin{array}{l}
x=X \cos (\omega t-\psi) \\
\varphi=\Phi \cos (\omega t-\psi)
\end{array}\right.
$$


By substituting these solutions in the equations at item (4), it shall be obtained the linear, uniform, algebraic system with the unknown $X$ and $\Phi$.

In order for thisalgebraic system to allow nonzero solutions, the determinant of the system must be zero. The equation of the natural angular frequencies $\left(\omega_{1}\right.$ and $\left.\omega_{2}\right)$ is obtained from this condition. By solving this equation, it follows that:

$$
\omega_{1}=\sqrt{\frac{B_{2}-\sqrt{B_{2}^{2}-4 B_{1} B_{3}}}{2 B_{1}}} ; \quad \omega_{1}=\sqrt{\frac{B_{2}+\sqrt{B_{2}^{2}-4 B_{1} B_{3}}}{2 B_{1}}} .
$$

where: $B_{1}=\left(\delta_{F} \alpha_{M}-\delta_{M} \alpha_{F}\right) m J_{C Z} ; B_{2}=\delta_{F} m+\left(\alpha_{F}+\delta_{M}\right) m h+\left(m h^{2}+J_{C Z}\right) \alpha_{M}+$ $\left(J_{C y}-J_{C Z}\right)\left(\delta_{F} \alpha_{M}-\delta_{M} \alpha_{F}\right) m \Omega^{2}$ and $B_{3}=\alpha_{M}\left(J_{C y}-J_{C Z}\right) \Omega^{2}+1$.

b) The case of the backward precession

By following the same calculation steps as in the case of the forward precession, there will be obtained the natural angular frequencies. The only difference is that the expression of the gyroscopic moment is substituted in all the equations:

$M_{g}=\left(J_{y}-J_{z}\right) \Omega^{2} \varphi$ substituted by $M_{g}=-\left(J_{y}+J_{z}\right) \Omega^{2} \varphi$. In other words, the expression $\left(J_{C y}-J_{C z}\right)$ shall be substituted by $-\left(J_{C y}+J_{C z}\right)$ in all equations.

\subsection{The fixing point of the basket on the shaft coincides with the centre of mass}

In this case $h=0$. Consequently, the equations by which there are determined the natural angular frequencies, regarding both the forward and the backward precession, are obtained out of the relations (4), (6) by substituting $h$ with $h=0$.

2.3The centre of mass is between the fixing point of the basket on the shaft andbearing

The study of the vibrations is similar with the one mentioned at item 2.1. The difference is that $h<0$. Consequently, the equations by which there are determined the natural angular frequencies, regarding both the forward and backward precession, are obtained out of the relations (4), (6) by substituting $h$ with $-h$.

\section{Vertical centrifuge with the basket in console}

\subsection{The fixing point of the basket is between the centre of mass and the bearing}

Just like in the case of the horizontal centrifuge with a console-mounted basket, in order to write the differential equations of the movement the method of influence coefficients is used. First of all the reactions in point $O$ must be calculated (fig.2,a). The basket is isolated, and the d'Alembert's principle is applied (fig.2,d).

Like in the 2.1 paragraph,finally it is obtained:

a) The case of forward precession (fig. $2, \mathrm{~d}$ )

$$
\left\{\begin{array}{l}
x=-\left(\delta_{F}+\delta_{M} h\right) m \ddot{x}-\left[\delta_{F} m h+\delta_{M}\left(m h^{2}+J_{C Z}\right)\right] \ddot{\varphi}-\delta_{M} a \varphi+\delta_{M B} m g x \\
\varphi=-\left(\alpha_{F}+\alpha_{M} h\right) m \ddot{x}-\left[\alpha_{F} m h+\alpha_{M}\left(m h^{2}+J_{C Z}\right)\right] \ddot{\varphi}-\alpha_{M} a \varphi+\alpha_{M B} m g x
\end{array}\right.
$$


where:

$a=\left(J_{C y}-J_{C z}\right) \Omega^{2}-m g h ; \delta_{M B}$ and $\alpha_{M B}$ - influence coefficients which represent the displacements in point $O$ produced by a moment equal to one unit placed in point $B$;

The calculus of the natural angular frequenciesis done like in the case of the horizontal centrifuge with a console mounted basket with formulas similar with (6).

b) The case of the backward precession

In the case of backward precession the gyroscopic moment $M_{g}$ tends to amplify the bending strain of the shaft and thus to reduce the stiffness of the shaft. Therefore, the direction of the gyroscopic moment is contrary to that of the resultant moment of the inertia forces system. This means that in the equations (7) the quantity $a=$ $\left(J_{C y}-J_{C z}\right) \Omega^{2}-m g h$ must be replaced with $a=-\left(J_{C y}+J_{C z}\right) \Omega^{2}-m g h$.

\subsection{The fixing point of the basket on the shaft coincides with the centre of mass}

If the fixing point of the basket to the shaft coincides with the centre of mass, then $h=0$. Thus, both in the case of forward and backward precession, the relations from which we determine the natural angular frequencies are obtained from the relations used in the 3.1 paragraph, through customization $h=0$.

\subsection{The centre of mass is located between the fixing point of the basket on the shaft and the bearing}

As against the case in which the fixing point of the basket is found between the centre of mass and the bearing, we have $h<0$. Thus, both in the case of forward and backward precession, the relations from which we determine the natural angular frequenciesare obtained from the relations used in the 3.1 paragraph, by replacing $h$ with $-h$.

\section{Horizontal centrifuge with the basket between the bearings}

\subsection{The fixing point of the basket is not situated at the middle of the distance between} the bearings

For all the cases (figure 5.a, b, c) are available the relations established in the case of the horizontal centrifuge with the basket in console $\left(2^{\text {nd }}\right.$ chapter $)$. Only the influence coefficients $\delta_{F}, \delta_{M}, \alpha_{F}, \alpha_{M}$ must be calculate.

\subsection{The fixing point of the basket on the shaft is situatedat the middle of the distance} between the bearings but it does not coincide with the centre of mass

In this case (figure 5.d), starting from the 4.1 paragraph the influence coefficients $\delta_{F}, \delta_{M}, \alpha_{F}, \alpha_{M}$ must be calculated.The values $\delta_{M}=0$ and $\alpha_{F}=0$ are obtained.

So, both in the case of forward and backward precession, the relations from which we determine the natural angular frequencies are obtained from the relations used in the 4.1 paragraph, by replacing $\delta_{M}=0$ and $\alpha_{F}=0$. 
Boiangiu, M. \& Boiangiu, A.: Influence of the Constructive and Operational Featu...

4.3 The fixing point of the basket on the shaft is situatedat the middle of the distance between the bearings and it coincides with the centre of mass

In this case (figure 5.e) the problem has one degree of freedom. The gyroscopic moment doesnot act. It is obtained for the natural angular frequencies the expression:

$$
\omega=\sqrt{\frac{1}{\delta_{F} m}}
$$

\section{Application}

It is considered a horizontal console centrifugal basket. The basket has the shape of a cylinder. The geometrical and mechanical characteristics of the shaft-basket system are the following: length of the shaft (including the console part): 0.8 m;diameter of the shaft: $0.08 \mathrm{~m}$; diameter of the basket: $0.5 \mathrm{~m}$; length of the basket: $0.12 \mathrm{~m}$;distance from the bearing to the fixing point of the basket: $0.05 \mathrm{~m}$;density of the material of the shaft and basket: $7800 \mathrm{Kg} / \mathrm{m}^{3}$; longitudinal modulus of elasticity (Young's modulus): $21 \times 10^{10} \mathrm{~N} / \mathrm{m}^{2}$; distance from the longitudinal axis of the basket to the centre of mass $(e): 0.003 \mathrm{~m}$.

As regards the coefficients of influence, there were obtained the following values: $\delta_{F}=1.3877 \quad \times 10^{-9} \quad \mathrm{mN}^{-1} ; \quad \delta_{M}=-2.5904 \times 10^{-8} \quad \mathrm{~N}^{-1} ; \quad \alpha_{F}=-2.5904 \times 10^{-8} \quad \mathrm{~N}^{-1}$; $\alpha_{M}=5.2055 \times 10^{-7} \mathrm{~m}^{-1} \cdot \mathrm{N}^{-1}$.

The mechanical moments of inertia: $J_{C y}=1.8755 \mathrm{~kg} \cdot \mathrm{m}^{2} ; J_{C y}=1.0628 \mathrm{~kg} \cdot \mathrm{m}^{2}$.

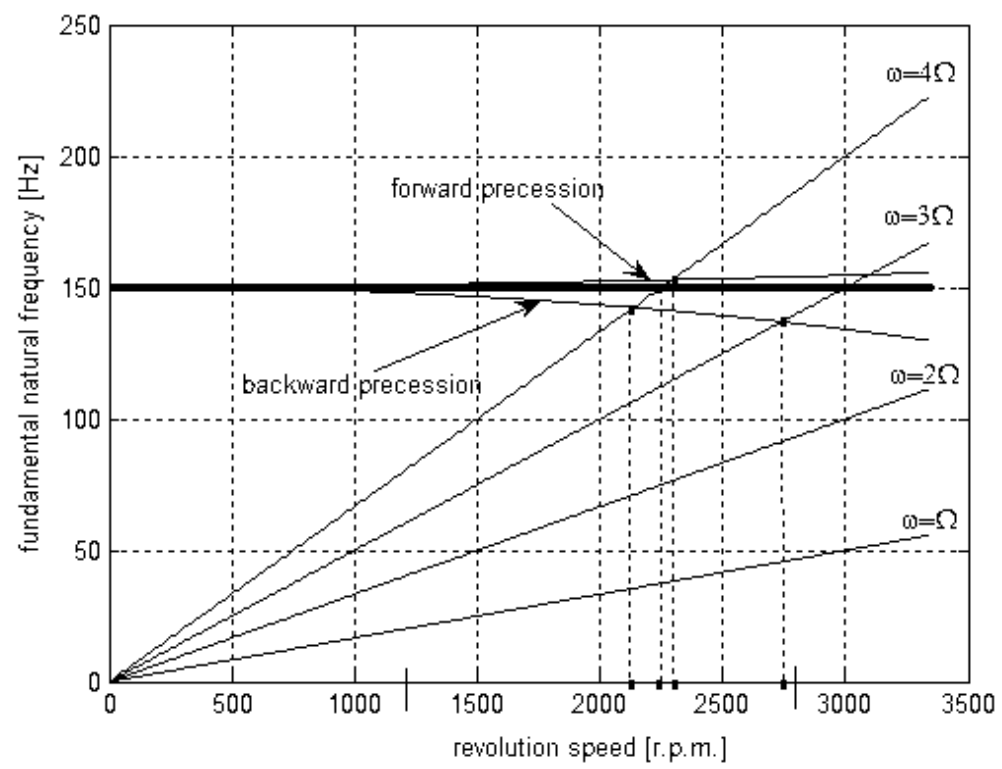

Fig. 7. Variation of the fundamental natural frequency $\left(v_{1}\right)$ depending on the speed

It is considered the case when the fixing point of the basket is between the centre of mass and the bearing. The natural angular frequencies were determined. Because the second angular frequency has a higher value, the first angular frequency, meaning the fundamental natural angular frequency $\left(\omega_{1}\right)$, shall be taken into consideration. Figure 7 presents the variation of the fundamental natural frequency, 
$v_{1}=\omega_{1} / 2 \pi$, depending on the speed. In order to determine the critical speeds, there have been presented the first four harmonics of the disturbing force. It can be observed that, regarding the considered operational domain of the centrifuge $(1200 \div$ 2800 r.p.m.), there are occurring critical speeds which correspond to the third and fourth harmonics. At the same time, it also can be observed that the forward precession leads to the increasing of the critical speeds, while the backward precession triggers the decreasing of the critical speeds.

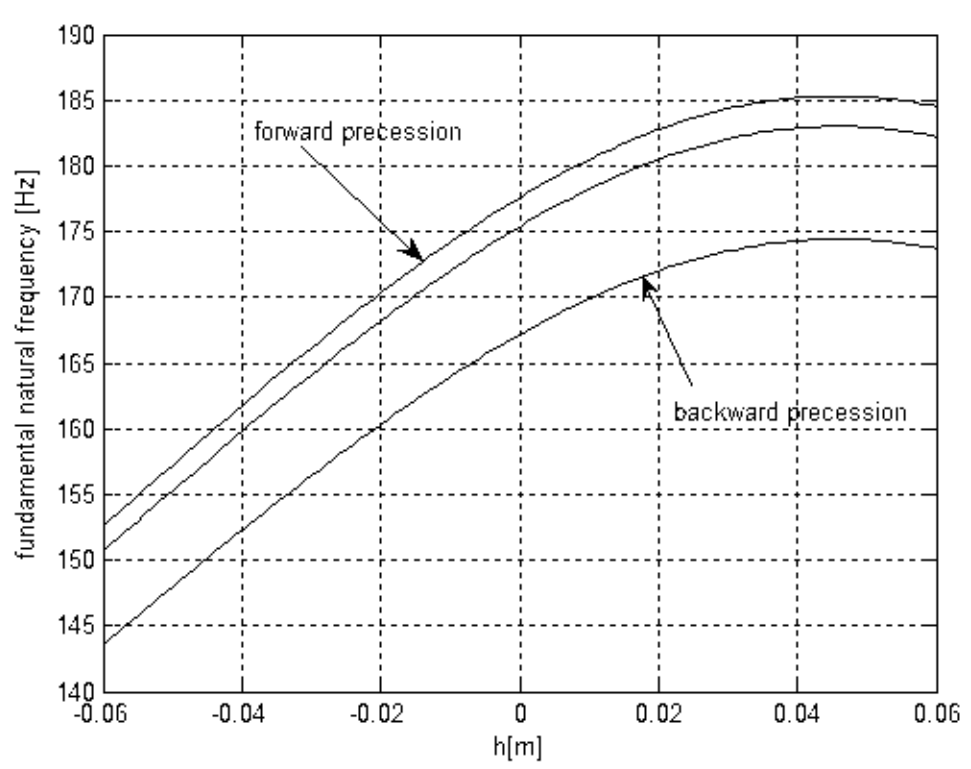

Fig. 8. Variation of the fundamental natural frequency $\left(v_{1}\right)$ depending on the position of the fixing point of the basket, with respectto the centre of mass

Figure 8 envisages the variation of the fundamental natural frequency, depending on the distance from the centre of mass to the fixing point of the basket, at 2000 r.p.m. The variation range is considered between $-0.06 \div 0.06 \mathrm{~m}$. It was considered $h<0$ when the fixing point of the basket stands between the centre of mass and the bearing. It can be observed that the lowest natural frequency values are obtained when $h<0$. When the distance from the centre of mass to the fixing point of the basket is decreasing and the fixing point of the basket passes after the centre of mass $(h>0)$ the fundamental natural frequency is increasing. In the case of the forward precession, the increase is of $16 \%$, while in the case of the backward precession, the increase is of $15 \%$.

While the centrifuge is in operation, the mass and the mechanical inertia moments of the basket will be modified as a result of the deposits on the sidewalls of the basket.

Figure 9 represents the variation of the fundamental natural frequency, depending on the lateral wall thickness of the basket, for a speed of 2000 r.p.m. The variation range is between $0.01 \div 0.03 \mathrm{~m}$. It can be observed that the thicker the lateral wall of the basket, the more decreases the fundamental natural frequency. This decrease is of approximately $29 \%$, in the case of backward precession, and of approximately $24 \%$, in the case of forward precession. 


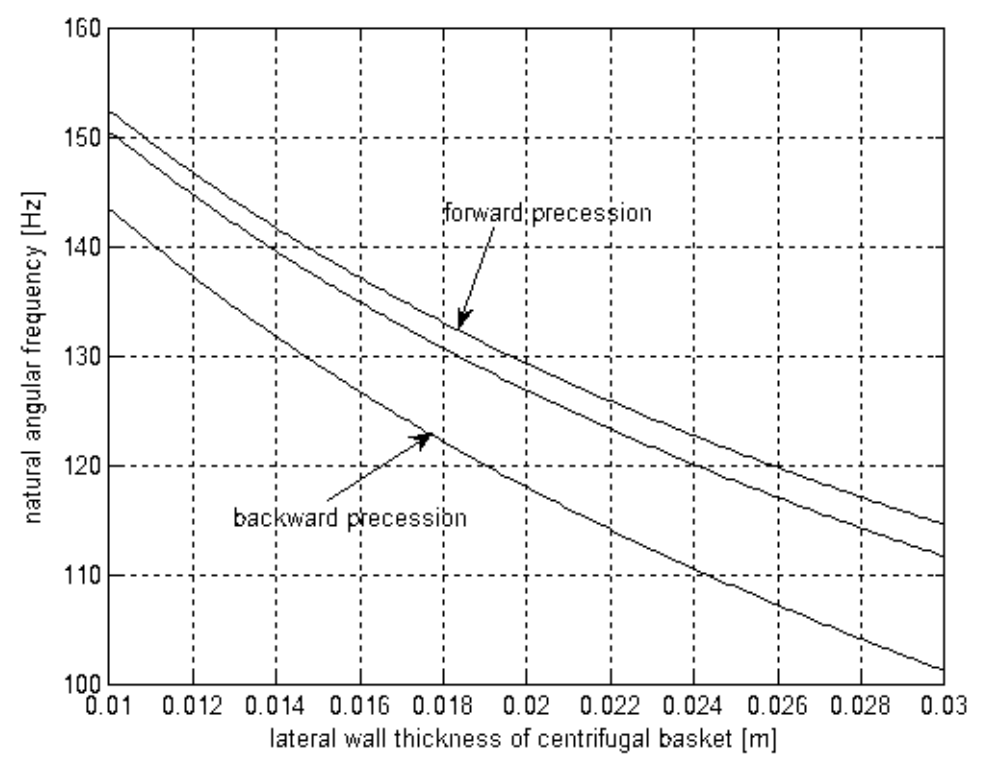

Fig. 9. Variation of the fundamental natural frequency $\left(v_{1}\right)$ depending on the lateral wall thickness of the basket

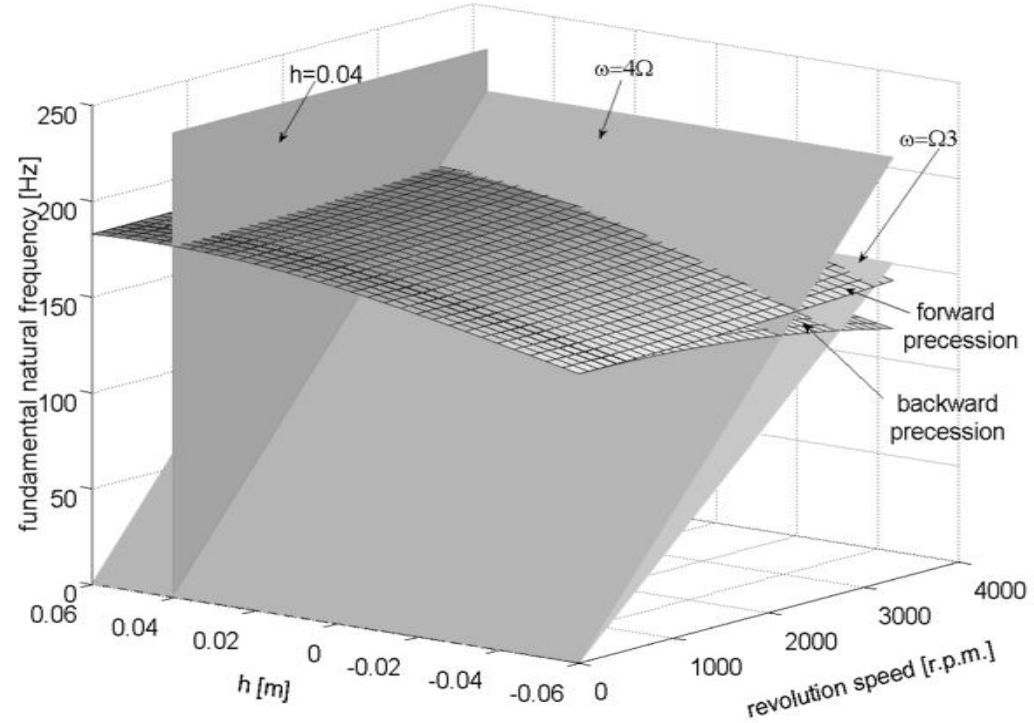

Fig. 10. Variation of the fundamental natural frequency $\left(v_{1}\right)$ depending on the speed and on the position of the fixing point of the basket

Figure 10 envisages the variation of the fundamental natural frequency, depending on the speed and on the distance from the centre of mass to the fixing point of the basket, for a $0.01 \mathrm{~m}$ thickness of the basket's wall. It can be noticed a significant decrease of the natural frequency, corresponding to the backward precession, when there are high speeds and negative values of the distance from the centre of mass to the fixing point of the basket. If it is designed a plane adequate to one of the $h$ values, it shall be obtained a diagram similar to the figure 7 .

Figure 11 represents the variation of the fundamental natural frequency, depending on the speed and on the wall thickness of the basket. Taking into account that, in the case of backward precession, as the speed is increasing the natural 
frequency is decreasing, it may be possible that the critical speeds to be highly reduced, if the wall of the basket becomes thicker (as a result of the deposits), triggering the possible critical speeds in the domain of adequate operation of some inferior harmonics (for instance, the second harmonic).

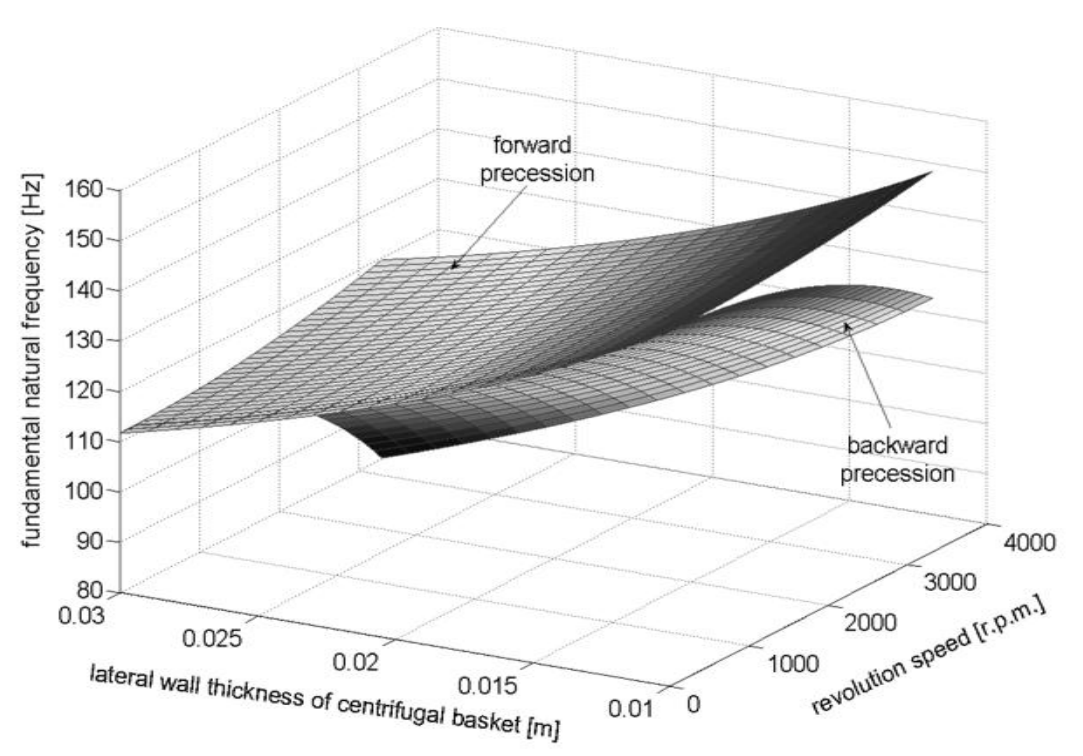

Fig. 11. The variation of the fundamental natural frequency $\left(v_{1}\right)$ depending on the speed and on the lateral wall thickness of the basket

The results obtained in the study of the horizontal centrifuge with the basket in console will are compared with the results obtained in the study of a vertical centrifuge with the basket in console.

It has been chosen for application a centrifuge with geometrical and mechanical features identical with those of the horizontal centrifuge with the basket in console studied before, in order to investigate in which extent the weight force of the basket influences the values of the natural angular frequencies of the vertical centrifuge.

Although in the calculation relations there are terms specific to the vertical centrifuges, which take into account the weight of the basket, their influence upon the results is rather low (up to $0.003 \%$ ). Thus, the results obtained in the study of the vibrations of horizontal centrifuges with a console-mounted basket may be applied as well without issues in the case of vertical centrifuges with a console-mounted basket.

The results obtained in the study of the horizontal centrifuge with the basket in console will are compared with the results obtained in a study of a horizontal centrifuge with the basket between the bearings.

It is considered a horizontal centrifuge with the basket between the bearings. The basket has the shape of a cylinder. It has been chosen for application a centrifuge with geometrical and mechanical features identical with those of the horizontal centrifuge with the basket in console (excepting the position of the basket), in order to investigate in which extent the position of the basket influences the values of the natural angular frequencies.

The geometrical and mechanical characteristics of the shaft-basket system are the following: length of the shaft: $0.75 \mathrm{~m}$; distance from the fixing point of the basket 
to the near bearing: $0.2 \mathrm{~m}$.

As regards the coefficients of influence, there were obtained the following values: $\delta_{F}=1.2737 \times 10^{-8} \quad \mathrm{mN}^{-1} ; \quad \delta_{M}=4.0526 \times 10^{-8} \quad \mathrm{~N}^{-1} ; \quad \alpha_{F}=4.0526 \times 10^{-8} \quad \mathrm{~N}^{-1}$; $\alpha_{M}=2.4473 \times 10^{-7} \mathrm{~m}^{-1} \cdot \mathrm{N}^{-1}$.

The mechanical moments of inertia: $J_{C y}=1.8755 \mathrm{~kg} \cdot \mathrm{m}^{2} ; J_{C y}=1.0628 \mathrm{~kg} \cdot \mathrm{m}^{2}$.

It is considered the case when the fixing point of the basket is not situated at the middle of the distance between the bearings. The fixing point of the basket is between the centre of mass and the bearing. The natural angular frequencies were determined. Because the second angular frequency has a higher value, the first angular frequency, meaning the fundamental natural angular frequency $\left(\omega_{1}\right)$, shall be taken into consideration. Figure 12 presents the variation of the fundamental natural frequency, depending on the speed. This is approximately 5\% higher than in the case of the centrifuge with the basket in console.In order to determine the critical speeds, there have been presented the first four harmonics of the disturbing force. It can be observed that, regarding the considered operational domain of the centrifuge $(1200 \div$ 2800 r.p.m.), there are occurring critical speeds which correspond to the fourth harmonic, as opposed to the case of the centrifuge with the basket in console where appear critical speeds which correspond to the third and fourth harmonics. The influence of the forward precession and backward precession is smaller than in the case of the centrifuge with the basket in console. That is why the critical speeds are contained in a narrow field (figure 12).

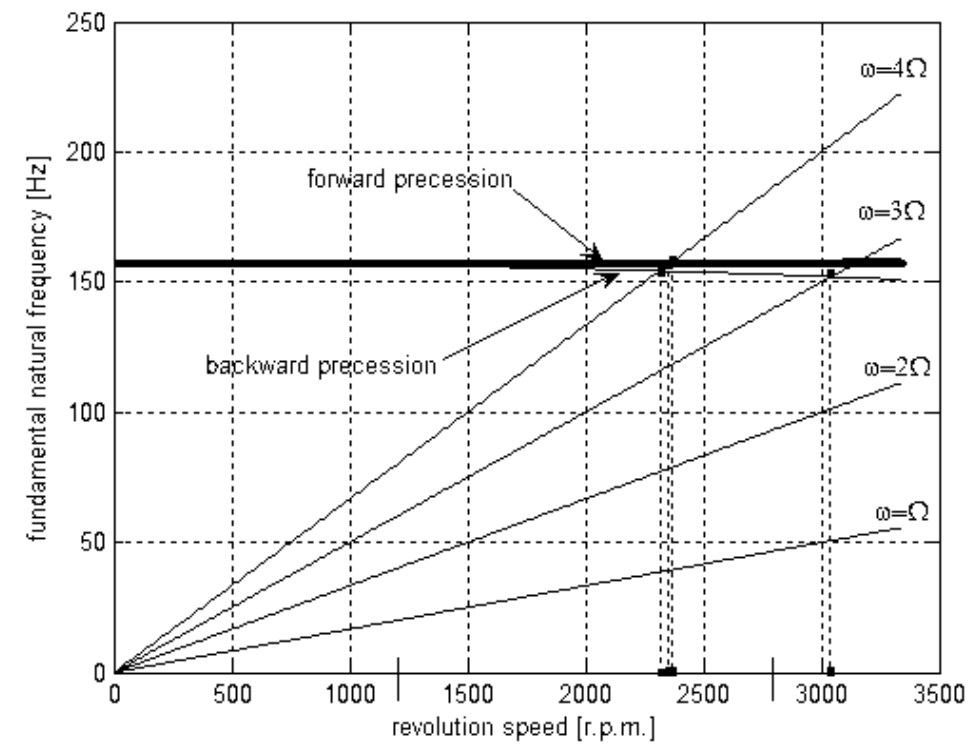

Fig. 12. Variation of the fundamental natural frequency $\left(v_{1}\right)$ depending on the speed

Figure 13 envisages the variation of the fundamental natural frequency, depending on the distance from the centre of mass to the fixing point of the basket, at 2000 r.p.m. The variation range is considered between $-0.06 \div 0.06 \mathrm{~m}$. It was considered $h<0$ when the fixing point of the basket stands between the centre of mass and the bearing. It can be observed that the lowest natural frequency values are obtained when $h<0$,just as in the case of the centrifuge with the basket in console. The forward precession and backward precessiondo not lead to big variations of the 
fundamental natural frequency. When the distance from the centre of mass to the fixing point of the basket is decreasing and the fixing point of the basket passes after the centre of mass $(h>0)$ the fundamental natural frequency is increasing. The increase is approximately $40 \%$, a lot bigger just as in the case of the centrifuge with the basket in console, when the increase is approximately $15-16 \%$.

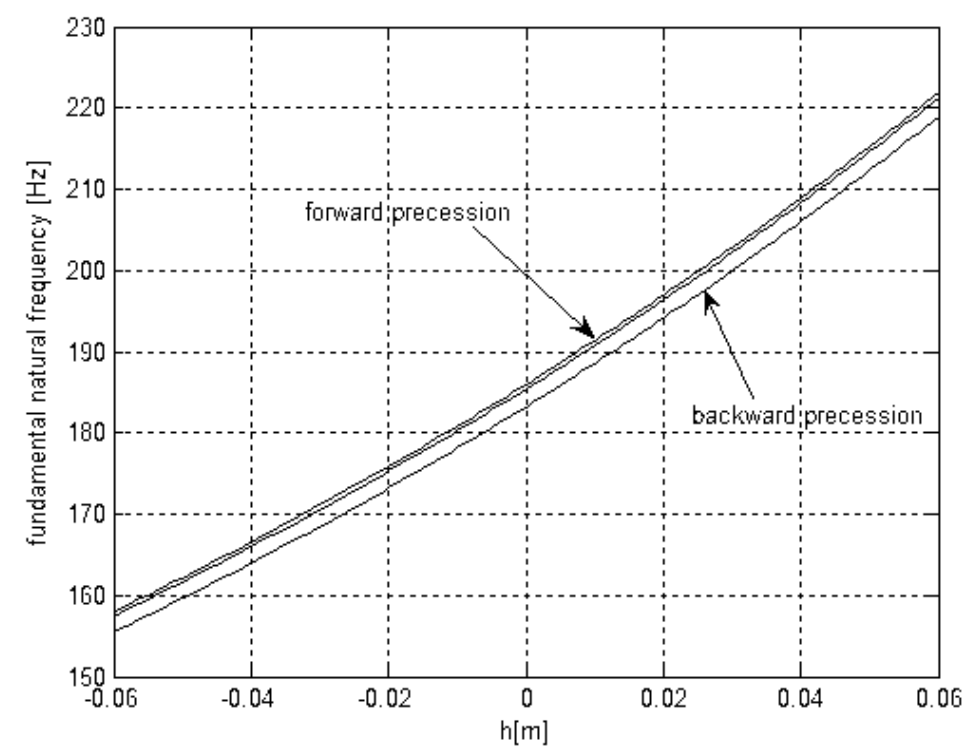

Fig. 13. Variation of the fundamental natural frequency $\left(v_{1}\right)$ depending on theposition of the fixing point of the basket, with respect to the centre of mass

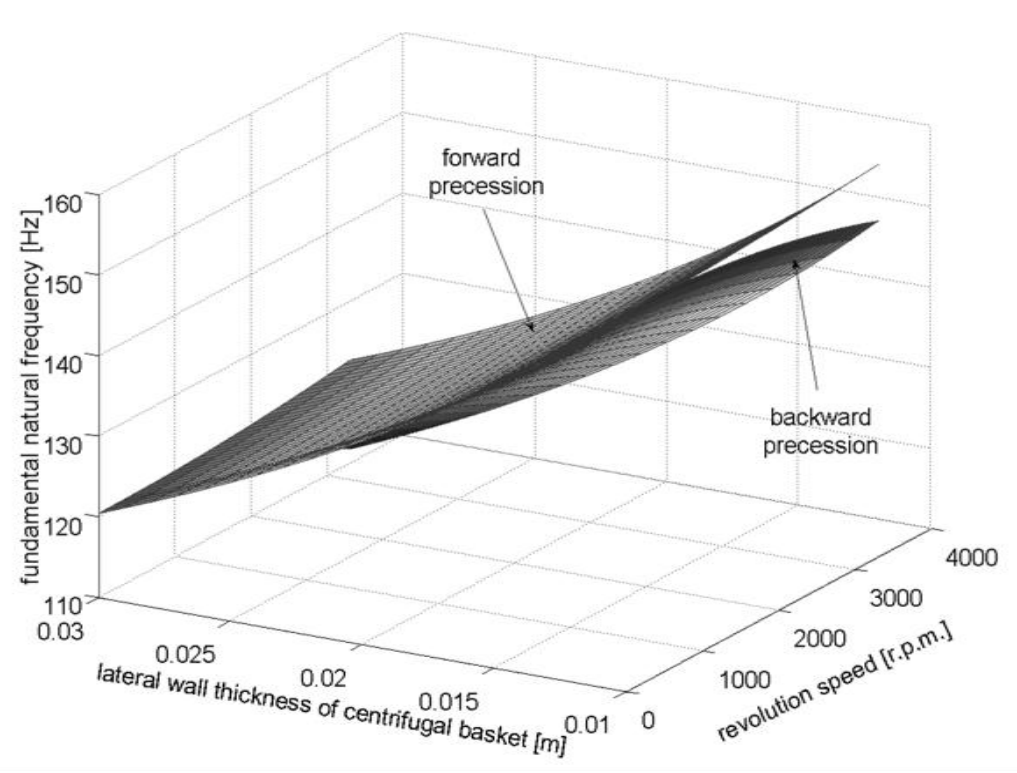

Fig. 14. Variation of the fundamental natural frequency $\left(v_{1}\right)$ depending on the speed and on the lateral wall thickness of the basket

Figure 14 represents the variation of the fundamental natural frequency, depending on the speed and on the wall thickness of the basket. The variation range is between $0.01 \div 0.03 \mathrm{~m}$. Unlike the centrifuge with the basket in console, the forward 
precession and backward precessiondo not lead to big variations of the fundamental natural frequency. For example, for a speed of 2000 r.p.m, the decrease is of approximately $24 \%$, in the case of backward precession, and of approximately $23 \%$, in the case of forward precession.

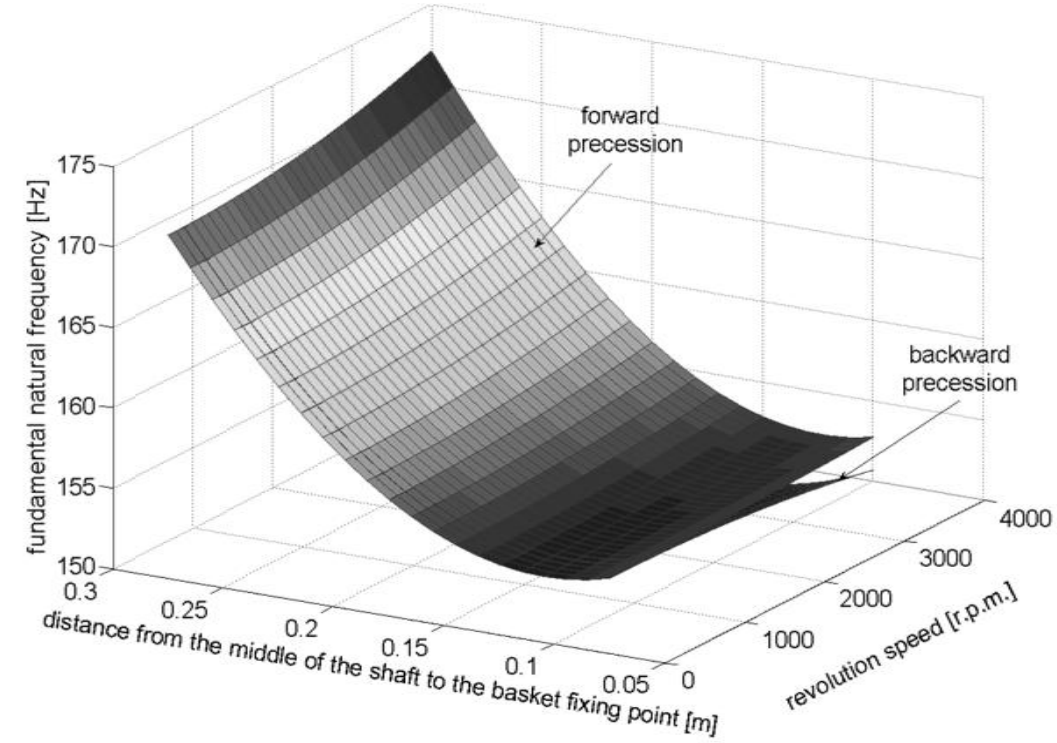

Fig. 15. Variation of the fundamental natural frequency $\left(v_{1}\right)$ depending on the speed and on the distance from the basket fixing point to the middle of the shaft

The variation of the fundamental natural frequency depending on the speed and on the distance from the basket fixing point to the middle of the shaft is represented in the figure 15.It can be observed that when the distance from the basket fixing point to the bearing is decreasing, the fundamental natural frequency is increasing up to $10 \%$, if the distance is $0.2 \mathrm{~m}$. The variation depending on the speed is small, up to $2 \%$. The forward precession and backward precessiondo not lead to big variations of the fundamental natural frequency.

The figure 16 represents the variation of the fundamental natural frequency depending on the distance from the left bearing to the basket fixing point and on the position of the basket fixing point with respect to the centre of mass. The fundamental natural frequency depends on the position of the fixing point of the basket with respect to the centre of mass, just as in the case of the centrifuge with the basket in console. In the case of the centrifuge with the basket between the bearings, this variation is depending on the position on the shaft of the fixing point of the basket. So, when the distance from the basket fixing point to the bearing is decreasing, the variation of the fundamental natural frequency depending on the position of the basket fixing point with respect to the centre of mass is increasing, up to $40 \%$. It was considered $h<0$ when the fixing point of the basket stands between the centre of mass and the bearing. It can be observed that the lowest fundamental natural frequency values are obtained when the fixing point of the basket stands between the centre of mass and the bearing, just as in the case of the centrifuge with the basket in console. When the distance from the basket fixing point to the centre of 
mass is decreasing and the fixing point of the basket passes after the centre of mass $(h>0)$ the fundamental natural frequency is increasing.

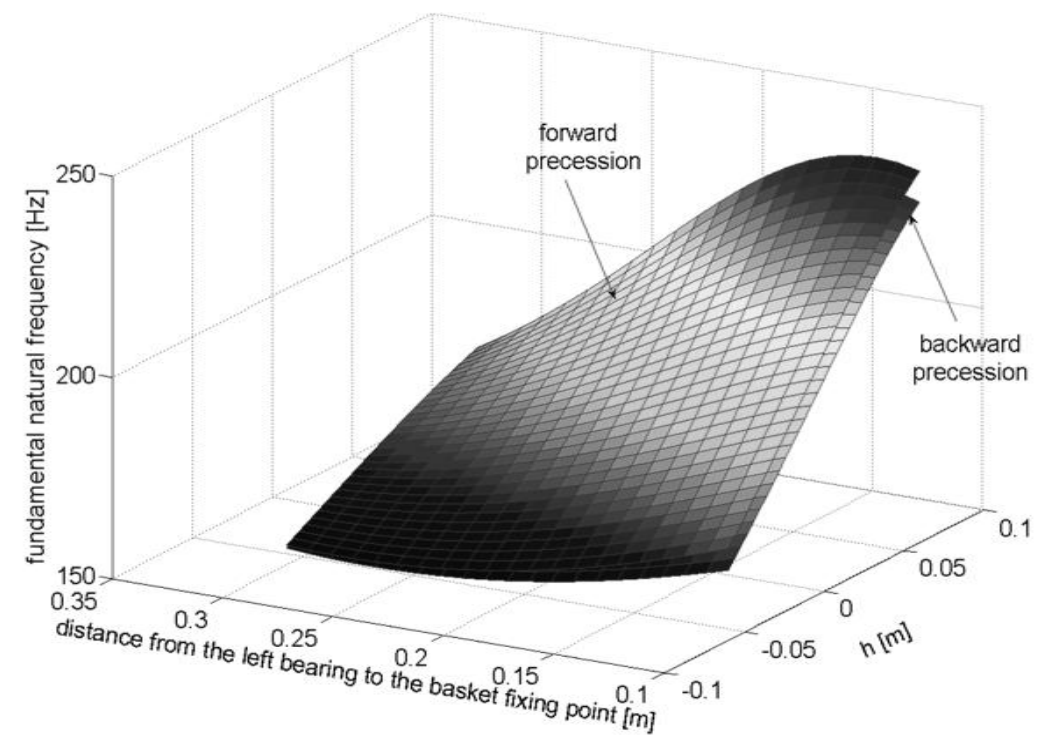

Fig. 16. Variation of the fundamental natural frequency depending on the distance from the left bearing to the basket fixing point and on the position of the basket fixing point with respect to the centre of mass

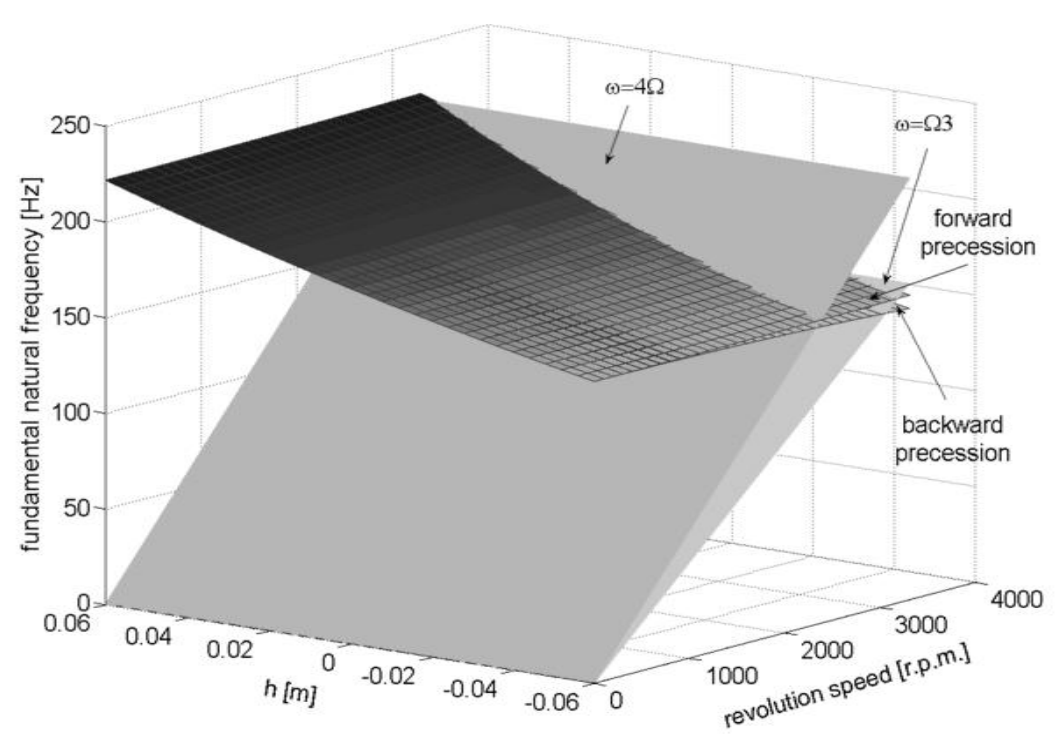

Fig. 17. Variation of the fundamental natural frequency $\left(v_{1}\right)$ depending on the speed and on the position of the fixing point of the basket with respect to the centre of mass

In the figure 10 is represented the variation of the fundamental natural frequency, depending on the speed and on the distance from the centre of mass to the fixing point of the basket, for a $0.01 \mathrm{~m}$ thickness of the basket's wall. The variation field for $h$ is $-0.06 \div 0.06 \mathrm{~m}$ and covers all the theoretical cases. It can be observed that the lowest natural frequency values are obtained when the fixing point of the basket stands between the centre of mass and the bearing. The variation of the fundamental 
natural frequency depending on the speed is smaller than the variation depending on the position of the basket fixing point with respect to the centre of mass. The influence of the forward precession and backward precession is smaller than in the case of the centrifuge with the basket in console.

\section{Conclusions}

Due to the constructive and operational features, during the operation of the centrifuges, it may appear modifications of the mechanical characteristics of these centrifuges, such as the modification of the position of the centres of mass and of the weight of the basket. The uneven deposits represent the cause. The result of these deposits is the alteration of the dynamic behaviour of the centrifuge, which consists in vibrations with amplitudes that cannot be neglected and that involve unusual sounds, wears in the bearings and a decreased quality of the products. The fact that the experts take into account a data set during designing and that this data set modifies during operation constitutes an issue that cannot allow the predictions of the dynamic behaviour of the centrifuge.

This paper proposes a simplified model of study of the influence of the constructive and operational features on the natural frequencies of the centrifuges.

The placing of the basket between the bearings leads to higher values of the fundamental natural frequency. The variation of the fundamental natural frequency depending on the distance from the basket fixing point to the centre of mass is bigger than in the case of the centrifuge with the basket in console. The forward precession and backward precession phenomena lead to small variations of the fundamental natural frequency depending on the speed. This fact leads to a narrow dispersion field for the critical speeds

The influence of the rigidity of the bearings upon the horizontal and the vertical centrifuges may represent the topic of another dissertation.

\section{References}

Haeberle, S.; Brenner, T.; Schlosser, H. P.; Zengerle, R. \& Ducree, J. (2005). Centrifugal Micromixery, Chemical Engineering \& Technology, Vol.28, Issue 5, May 2005, pp. 613-616, ISSN 0930-7516

Iatan, R. et al. (1990). Calculul si constructia tamburelor centrifugelor; Stari de deformatii si de tensiuni in fundurile circulare plane, Revista de Chimie, No. 1, 1990, pp. 67, ISSN 0034-7752

Jinescu, V. (1998). Utilaj tehnologic pentru industria de proces, Editura Tehnica, ISBN 978-973-31-2357-6, Bucharest

Stiborsky, M. \& Anlauf, H. (2003). Prediction of centrifugal Deliquoring for Changing Particle Composition, Chemical Engineering \& Technology, Vol. 26, Issue 5, May 2003, pp. 553-557, ISSN 0930-7516

Sutherland, K. \& Records, A. (2001). Decanter centrifuge, Handbook, ISBN 1856173-69-0, Elsevier 